

\section{Social and Economic}

\section{Sustainability Analysis of Rural} Settlements Located in the

\section{Hazard-Prone Areas}

\section{(Case Study: Villages Surrounding the City of Sanandaj)}

\section{H. Kuhestani Eynul-din, A. Ahmadi, S. Ahmadi}

ABSTRACT - This study is aimed at analyzing economic and social sustainability of rural settlements in the hazard - prone zones. Accordingly, the present descriptive analytical study with emphasizing on its practical aspect is trying to identify high risk zones to locate the villages surrounding the Sanandaj City using Geography Information System (GIS) and Analytic Hierarchy Process (AHP). In this regard, for zoning of hazard - prone areas, information layers such as distance from the fault, gradient layer, height layer, distance from the river, landslide layer, and soil type layer were created utilizing the information existent in the database of GIS at Sanandaj Municipality. Finally, hazard - prone zones were identified by applying the technique in ARCGISIO and its practical functions and algorithms. In the next step, the layers of villages surrounding Sanandaj City were adapted to the prioritized zones and so the villages (Salavat Abad, Dolat Abad, Gazar Dareh, Khalijan, Issa Dar, Hassan Abad) which are located in hazard - prone zoning, were identified. To assess the socio - economic conditions of these villages are used FTOPSIS technique. The studied samples were two Councils members in each village which were selected randomly to survey and to achieve the goal of research. The results showed that economical aspect of the indicator (rural road networks), with ID = E5, and social aspect of the indicator (health facilities), with ID =E8 gained the lowest weights in the minimum, average and maximum fuzzy criterion, $\left(\widetilde{\boldsymbol{W}}_{i}\right)$ and also the indictor of rural power network and its backup services, with $I D=E 1$, and taking care of 
villages with cultural and historical monuments gained the highest weights in the minimum, average and maximum fuzzy criterion $\left(\widetilde{\boldsymbol{W}}_{i}\right)$.

\section{KEY WORDS: SUSTAINABLE DEVELOPMENT, SOCIAL AND ECONOMIC CONDITION, HAZARD PRONE AREAS, SANANDAJ.}

\section{INTRODUCTION}

Different types of natural hazards and their influences as unrepeatable and destructive phenomena have always been existed during the life of the Earth and human life is faced with their potential threads. Accordingly, we can conclude that no society can claim immunity from natural hazards and humans are always encountered their subjective and objective adverse effects (Mose and Pathrankul, 2006: 396). However, despite scientific and technical advances during recent decades, human and non-human communities, damage heavily by natural hazards, especially villages as the most important and most sensitive areas which are highly vulnerable to theses natural hazards.

Following modern developments, cities and villages witnessed changes such as imbalanced and uncoordinated rapid population growth and physical growth of cities and villages (Husseini et al, 2010: 2). In recent decades, uncontrolled and disorganized physical developments in the cities and villages lead to change in their structure and their role considerably and also become unclear their future physical compatibility (Dalir et al, 2006: 213-216). Here the most important thing is to identify the prioritized zones to settle in places away from environmental hazards. In many cases these hazards influence destructively on both urban and rural human communities which their environmental, social, economic and psychological consequences will be tangible for many years in and Ghasemi Barfi, 2006). Kurdistan Province with more than 82 percent in mountainous area is located on the Zagros belt. So 77 percent of rural settlements are located in the mountainous areas (Statistical Center of Iran, 2007: 65). The study area in this research is 22 villages surrounded Sanandaj City. Considering that too many people are lived in these settlements, it is of crucial importance to identify and assess the social and economic conditions of villages located in this hazard - prone areas. The zoning of hazard - prone villages surrounded by Sannandaj using natural and environmental factors (height, slope, fault, landslide layer, soil type, etc) is the aim of this study. Finally, the assessment of stability of socio - economic conditions of hazard - prone areas is performed by multi - criteria decision analysis method. Obviously, our results can be help managers and experts in order to provide appropriate policies on rural development. 


\section{THEORETICAL FOUNDATIONS}

Sustainable development is a comprehensive approach to improve the quality of human life in order to achieve economic, social and environmental welfare of human settlements (Torjman, 2000: 2). Sustainable development aims to lead human society to a well, viable and sustainable place through economic development, social progress and environmental responsibility (Cornelissen, 2007: 173).

Sustainable development is essentially not a comprehensive plan or an initial plan to order the final stage of a collection. Indeed, sustainable development is not an object, but a dynamic process. It is basically a way of thinking about how should I go on this way to be able to see the present needs without threatening the ability of future generations to meet their needs. In addition to the fact that sustainable development is a collaborative process, which is considered justice among all generations (Lock, 2003), today it is also seeking to the separation of the urban and rural spatial functions and their following disturbance effects which in recent decades have been the dominant traditional pattern of planning in developing countries. Sustainable development has been emphasized on integrated policies by applying targeted and systematic economic, social and environmental approaches. In rural areas, factors such as economic, social, environmental and spatial processes, resources, energy, climate, etc. which have different functions affect the rural settlements. Each of the functions which are able to regulate relations between the regions and also providing environmental stability and living conditions for physical expansion of rural area are considered suitable (Pur Taheri, Naghavi, 2011: 58).

Development strategy of rural settlements is to provide management conditions for sustainable development of rural settlements. An integrated development of management with the aim of organizing the spatial and population distribution, facilities and infrastructural services to link overall context of rural areas are also considered in rural settlements (Kornecki, 2005: 39).If rural sustainable development means the management of rural areas to meet the needs of the present generation without comprising the ability of future generations to meet their own need, development planning based on the sustainable development leads to sustainability in all aspects of rural settlements. Therefore, sustainable development is seeking to connect and organize economy, environment and society, systematically (Burger, 1997: 3).

What we should be considered is that from 1980s onwards, the process of sustainable development, like an open umbrella extends its scope to various aspects of development and today become the ideal goal for all communities (Greenwood J, 1999: 71). Undoubtedly, the preparation of production possibilities, environmental abilities, 
assessment of natural conditions, and targeted exploitation of these potentials are among tools to achieve development and improving living standards and relative prosperity in any society. Complexity of socio - economic issues and multidimensional aspects of development and the need to quantifiable and measurable of these concepts led to be invented methods and techniques to operationalize and measure qualitative phenomena (Kalantari, 2008: 56). Planning for development of rural settlements as part of rural development planning including rural infrastructure projects such as road, water, electricity, improvement of physical fabric, facilities and services prepare the way for economic, social and cultural development. Although the physical development emphasized on providing rural requirements, these planning will affect the development of the rural development, directly and indirectly.

In this regard, sustainability assessment is usually considered as part of the assessment process of various aspects of sustainable development's effect (FME, 2007: 8). Therefore, sustainability evaluation reflects the measurement and assessment, and as an important tool is applied to change the conditions along with sustainable development in rural and urban areas (Pope \& Annandale, 2004: 596). Considering sustainable development, this study is done with an emphasis on the rural sector

\section{PROCEDURE AND CASE STUDY}

Sanandaj city of Kurdistan province with an area of 2,906 square kilometers locates between 35 degrees and 1 minute to 35 degrees and 32 minutes of north latitude and 46 degrees and 18 minutes to 47 degrees and 16 minutes of east longitude from prime meridian and places in an average height above sea level in Kurdistan region in Zagros Mountains in central front bowed to southern province (Ahmadi et all, 2011).The studied villages including 22 villages (Hanis, Khyare, Garmidare, Dushan, Grizeh, Vajidkane, Qar, Qaradiyan, Salavat Abad, Khanqah Sanandaj, Gadmiran, Asavaleh, Dolat Abad, Barazen, Qeshlaq, Naiser, Khalijan, Issa Dar, Gazar Darreh, Hassan Abad), which their total population is 32078 people. 


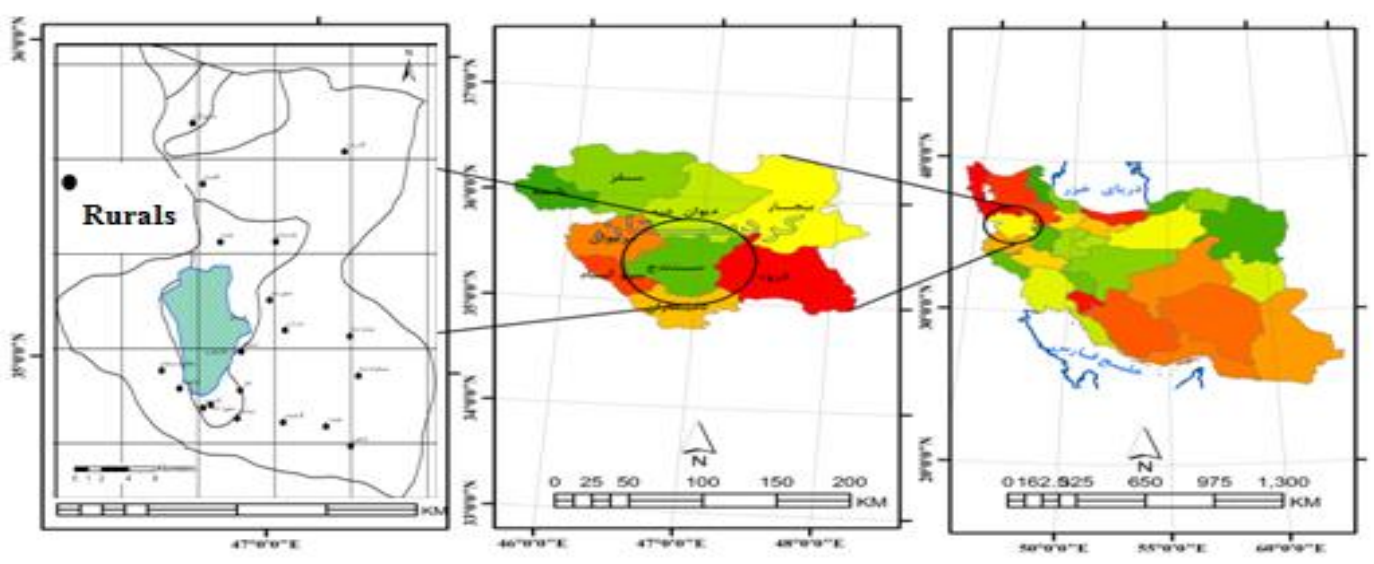

Fig 1. The studied villages which surrounds the Sanandaj City

In regard to, the research method is descriptive - analytic. To assess the sustainability of socio - economic conditions of the rural areas surrounding the city of Sanandaj and in connection with the risk-prone villages, the first step to achieve the research goal was to identify villages which are located in the risk-prone zones. Thus, it should be prepared and analyzed the criteria and constraints as layers in the map in order to zone the hazardous areas in Geographic Information System (GIS). In this study, with an emphasis on natural factors, the information layers such as (distance from the zone, the gradient layer, the height layer, distance from the layer, landslide layer, the soil type layer) was used to zone the hazardous areas. To analyze the zoning was used Analytical Hierarchy Process (AHP) model. Given the methodology and principle, AHP includes the following main steps:

1. Creating a binary comparison matrix

2. Calculating the criteria weights

3. Estimating the proportion of agreement (Malczewski, 1999).

After creating information layers (Maps No. 1-6) and implementing hierarchical analysis of the layers, hazard - prone zones surrounding the Sanandaj city were identifies, here the numbers of $1-5$ are suitable zones to rural settlements, it means that number 5 are among risk - prone areas with poor conditions (Map No. 7-8). 

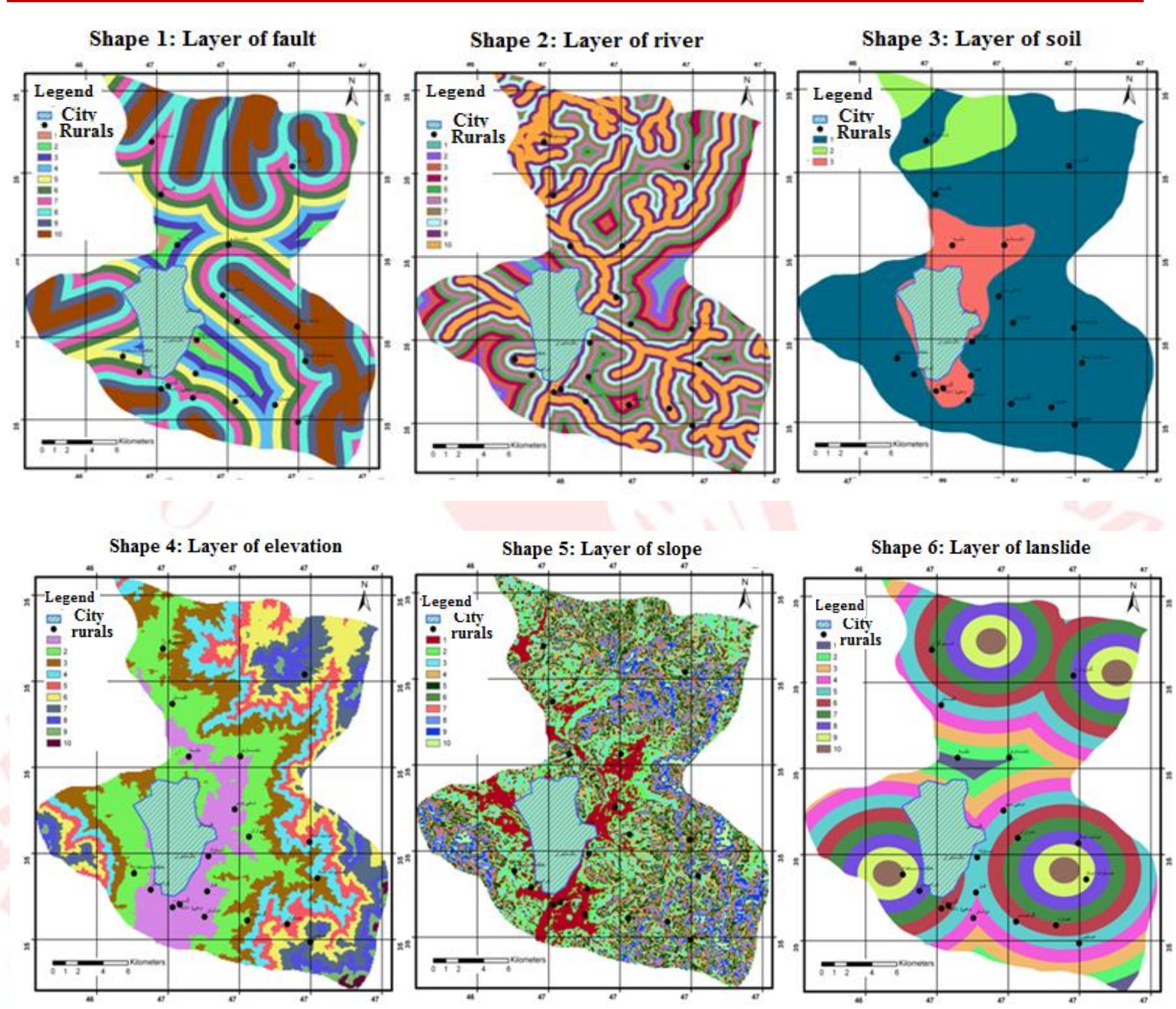


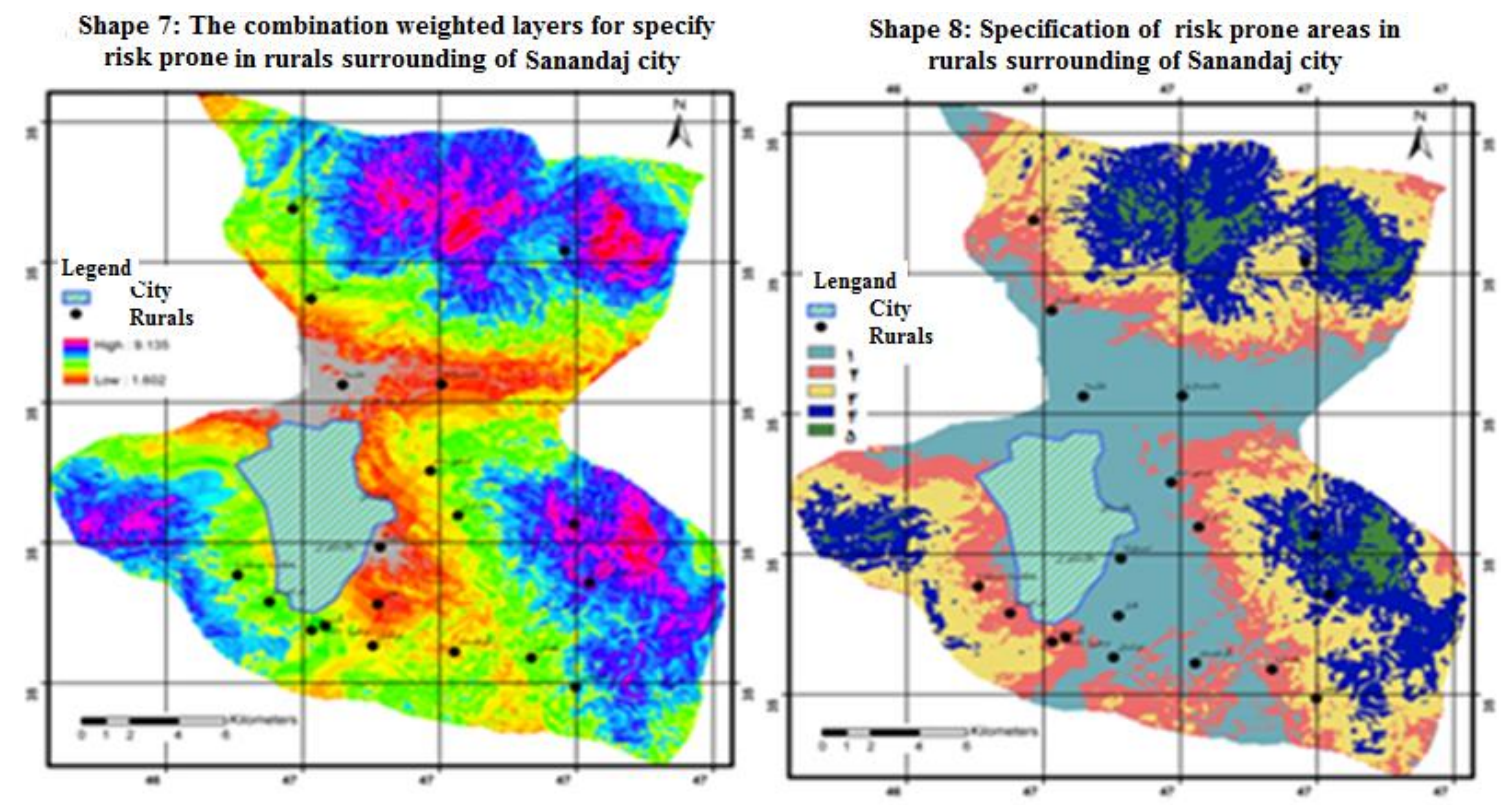

Finally, by adapting of rural areas layers in hazard - prone zones, villages which are located in hazardous zone were identified (Salavat Abad, Dolat Abad, Gazar Dare, Khalijan, Isaa Dar, Hassan Abad). In the next stage, with emphasis on sustainable development approach and using a combining technique FTOPSIS, the socio - economic conditions in these villages were evaluated as follow: Therefore, in this study to assess the sustainability of rural settlements which are located in the hazard - prone zones, first were extracted the required criteria from various sources (Table: 1). Accordingly, to operationalize the methodology using the identified criteria was designed a questionnaire and was distributed in 6 villages among rural Islamic Councils in a stratified random manner. In total were selected 12 samples, namely 2 Council members from each village.

To analyze the questionnaires is used Fuzzy - TOPSIS techniques. In fact, this method is generalizing TOPSIS method in the management science in which experts or specialists' predictions was expressed in absolute numbers (Azar and Faraji, 2002). The theory is able to express many of inaccurate concepts and statements with mathematical language and provide the conditions to reasoning, inference, control and decision - making in the uncertainty cases (Zahed, 1965: 38-53). 
Table (1): Dimensions and Indicators to assess social and economic conditions in rural settlements with an emphasis on sustainable development approach

\begin{tabular}{|l|c|}
\hline Indicators of sustainable development & $\begin{array}{c}\text { Dimensions of sustainable } \\
\text { development }\end{array}$ \\
\hline $\begin{array}{l}\text { The allocated development funds } \\
\text { Retrofitting rural houses }\end{array}$ & Dimensions of Economic \\
Substandard housing & \\
Rural road networks & Dimensions of Social \\
\hline $\begin{array}{l}\text { Population growth rate } \\
\text { Training and educational facilities } \\
\text { Clean drinking water }\end{array}$ & \\
Health facilities & \\
The ICT offices & \\
Private residential homes & \\
Rural Islamic Council and Rural Municipality (Dehyari) \\
Taking care of villages with cultural and historical \\
monuments
\end{tabular}

Source: (Purtaheri et al, 2011: 37-39)

To analyze the questionnaires is used Fuzzy - TOPSIS techniques. In fact, this method is generalizing TOPSIS method in the management science in which experts or specialists' predictions was expressed in absolute numbers (Azar and Faraji, 2002). The theory is able to express many of inaccurate concepts and statements with mathematical language and provide the conditions to reasoning, inference, control and decision - making in the uncertainty cases (Zahed, 1965: 38-53). In this theory, a fuzzy number is a special fuzzy set $\tilde{A}=x \in R / \mu_{\tilde{A}}(x)$, in which $\mathrm{X}$ accepts real values of set $\mathrm{R}$, and its membership function is $\mu_{\tilde{A}}(x)$. The most used fuzzy numbers are triangular and trapezoidal fuzzy numbers. Because of simple calculation of triangular fuzzy numbers, they are mostly used. Therefore, in this study we use triangular fuzzy numbers, too. A triangular fuzzy numbers $A$ is defined as a number with piecewise linear membership function $\mu_{A}$ in the form of equation (1):

$\mu_{x}(x)=\left\{\begin{array}{cc}\left(x-a^{1}\right) /\left(a^{m}-a^{1}\right), & a^{1} \leq x<a^{m} \\ 1, & x=a^{m} \\ \left(a^{r}-x\right) /\left(a^{r}-a^{m}\right), & a^{m}<x \leq a^{r} \\ 0, & \text { otherwise }\end{array}\right.$ 
This can be shown as triangular fuzzy numbers $\left(a^{1}, a^{m}, a^{r}\right)$. Figure 4 shows the membership function.

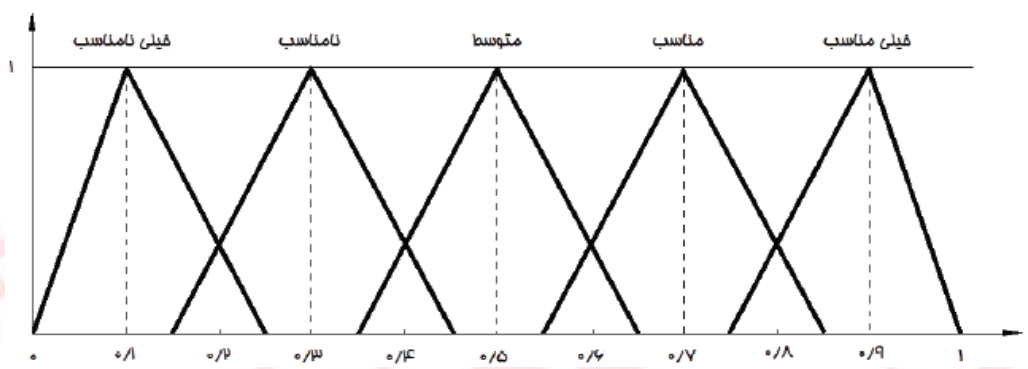

Fig. 4: triangular fuzzy number

If $A=\left(a^{1}, a^{m}, a^{r}\right)$ and $B=\left(b^{1}, b^{m}, b^{r}\right)$ were two triangular fyzzy numbers, distance function of $d(A, B)$ is defined as follow (Chang, 2002: 166-17-67):

$$
d(A, B)=\sqrt{\frac{1}{3}\left[\left(a^{l}-b^{l}\right)^{2}+\left(a^{m}-b^{m}\right)^{2}+\left(a^{r}-b^{r}\right)^{2}\right]}
$$

In this model, after using the experts' opinions in the first stage, the next step is to calculate the fuzzy numbers $\tilde{a}_{i j}$. Given the choice of triangular fuzzy numbers in this model, the numbers are defined as the following four relations:
(3): $a_{i j}=\left(\alpha_{i j}, \beta_{i j}, \gamma_{i j}\right.$
(4): $\alpha_{i j}=\operatorname{Min}\left(\beta_{i j k}\right), k=1, \ldots, n$
(5): $\delta_{i j}=\left(\prod_{k=1}^{n} \beta_{i j k}\right)^{1 / 3}$
(6): $\quad \gamma_{i j}=\operatorname{Max}\left(\beta_{i j k}\right), k=1, \ldots, n$

Table (2): Linguistic variables to assess the importance of indicators

\begin{tabular}{|c|c|}
\hline The importance of indicator & Fuzzy number \\
\hline Much less important & $(0,0,0 / 1)$ \\
\hline Less important & $(0,0 / 1,0 / 3)$ \\
\hline Somewhat less important & $(0 / 1,0 / 3,0 / 5)$ \\
\hline Indifferent & $(0 / 3,0 / 5,0 / 7)$ \\
\hline Somewhat important & $(0 / 5,0 / 7,0 / 9)$ \\
\hline Important & $(0 / 7,0 / 9,1)$ \\
\hline Very important & $(0 / 9,1,1)$ \\
\hline
\end{tabular}

Source: (Ataee, 2010: 54) 
In the above equations, $\beta_{i j}$ represents the relative importance of the parameter $\mathrm{i}$ compared to parameter $\mathrm{j}$ from kth experts points of view, $\gamma_{i j}$ and $\alpha_{i j}$ are upper limit and lower limit of experts' opinions for research variables, respectively. In these relationships $\delta_{i j}$ is geometric mean of experts' opinions. Obviously, fuzzy components are defined so that to be as $\gamma_{i j} \leq \delta_{i j} \leq \alpha_{i j}$.

In Table (2) there are component values or fuzzy numbers to present experts ' valuation of the research indicators. In the following, after quantifying indicators in Table (1), matrix of the required indicators is formed as follow:

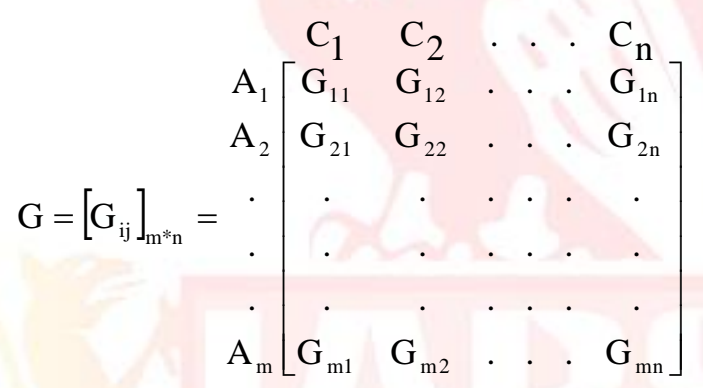

Here $A_{1}, A_{2}, \ldots, A_{m}$ are possible options, which should be evaluated by experts. $C_{1}, C_{2}$, $\ldots, C_{n}$ are criteria which have been considered relative to the options. $G_{i j}$ is the rank of $A_{i}$ against the criteria of $\mathrm{C}_{\mathrm{j}}$ and $\mathrm{W}_{\mathrm{j}}$ is the weight of $\mathrm{C}_{\mathrm{j}}$. In the evaluation process of theses weights, the importance degree of criteria provided by experts (here, Councils) are represented by linguistic terms (Wang, 2008: 1837-1845).

Suppose that $b_{i j}(e)$ represents the indicator value of $j$ in the cycle of $e$, where $\mathrm{i}=1,2, \ldots, \mathrm{m}, \mathrm{j}=1,2, \ldots, \mathrm{n}, \mathrm{e}=1,2, \ldots, \mathrm{t}$.

According to the concept of triangular fuzzy numbers is defined $\mathrm{G}_{\mathrm{ij}}$, in which:

$$
\begin{aligned}
& G_{i j}=\left(g_{i j}^{l}, g_{i j}^{m}, g_{i j}^{r}\right) \\
& \mathrm{g}_{\mathrm{ij}}^{\mathrm{l}}=\min \left\{\mathrm{b}_{\mathrm{ij}}(\mathrm{e}) \mid \mathrm{e}=1,2, \ldots, \mathrm{t}\right\} \\
& \mathrm{g}_{\mathrm{ij}}^{\mathrm{m}}=\frac{1}{\mathrm{t}} \sum_{\mathrm{e}=1}^{\mathrm{t}} \mathrm{b}_{\mathrm{ij}}(\mathrm{e}) \\
& \mathrm{g}_{\mathrm{ij}}^{\mathrm{r}}=\max \left\{\mathrm{b}_{\mathrm{ij}}(\mathrm{e}) \mid \mathrm{e}=1,2, \ldots, \mathrm{t}\right\}
\end{aligned}
$$


So, $\left[G_{i 1}, G_{i 2}, \ldots, G_{i n}\right]$ indicates the performance ratings of $A_{i}$ in the $n$ criteria. In the following, using the operators of MAX and MIN are identified positive ideal solutions $\left(\mathrm{A}^{+}\right)$and negative ideal solutions $\left(\mathrm{A}^{-}\right)$to option sets.

$\mathrm{A}^{-}=\left[\mathrm{G}_{1}{ }^{-}, \mathrm{G}_{2}^{-}, \ldots, \mathrm{G}_{\mathrm{n}}{ }^{-}\right]$

$\mathrm{A}^{+}=\left[\mathrm{G}_{1}^{+}, \mathrm{G}_{2}^{+}, \ldots, \mathrm{G}_{\mathrm{n}}^{+}\right]$

In the above relations, $\mathrm{G}_{\mathrm{n}}^{-}$and $\mathrm{G}_{\mathrm{n}}^{+}$which are triangular numbers as in equation (9), respectively have been formed from the minimum and maximum values of $g_{i j}^{1}$ ' $g^{m}{ }_{i j}, g^{r}$ ij for nth option. $\mathrm{d}_{\mathrm{ij}}{ }^{-} \mathrm{gd}_{\mathrm{ij}}{ }^{+}$indicated the distance of $\mathrm{G}_{\mathrm{ij}}$ from $\mathrm{G}_{\mathrm{j}}^{-}$and $\mathrm{G}_{\mathrm{j}}^{+}$which are calculated using the following formula:

$$
\begin{aligned}
& d_{i j}^{-}=d\left(G_{i j}, G_{j}^{-}\right)=\sqrt{\frac{1}{3}\left[\left(g_{i j}^{l}-g_{j}^{l-}\right)^{2}+\left(g_{i j}^{m}-g_{j}^{m-}\right)^{2}+\left(g_{i j}^{r}-g_{j}^{r-}\right)^{2}\right.} \\
&(\mathrm{i}=1,2, \ldots, \mathrm{m}),(\mathrm{j}=1,2, \ldots, \mathrm{n}) \\
& d_{i j}^{+}=d\left(G_{i j}, G_{j}^{l+}\right)=\sqrt{\frac{1}{3}\left[\left(g_{i j}^{l}-g_{j}^{l+}\right)^{2}+\left(g_{i j}^{m}-g_{j}^{m+}\right)^{2}+\left(g_{i j}^{r}-g_{j}^{r+}\right)^{2}\right.} \\
&(\mathrm{i}=1,2, \ldots, \mathrm{m}),(\mathrm{j}=1,2, \ldots, \mathrm{n})
\end{aligned}
$$

To determine the Importance Coefficient of multiple criteria of decision - making is used fuzzy numbers. So $W_{j k}=\left(w_{j k}^{l}, w_{j k}^{m}, w_{j k}^{r}\right)$ is a triangular fuzzy number which represents the expressed linguistic weights by expert $E_{k}$ regarding the criteria $C_{j}$ in the form of $(\mathrm{j}=1,2, \ldots, \mathrm{n})$ and $(\mathrm{k}=1,2, \ldots, \mathrm{p})$.

We consider $\mathrm{W}_{\mathrm{j}}$ as mean standard weight $\mathrm{C}_{\mathrm{j}}$ and we calculate it using the following equation:

$$
\begin{gathered}
W_{j}=\left(w_{j}^{l}, w_{j}^{m}, w_{j}^{r}\right)=(1 / p) \otimes\left(W_{j 1} \oplus W_{j 2} \oplus W_{j 3} \oplus \ldots \oplus W_{j p}\right) \\
\quad(\mathrm{j}=1,2, \ldots, \mathrm{n})
\end{gathered}
$$

The signs of $\oplus$ and $\otimes$ represent the fuzzy multiplication and addition. Finally, closeness coefficient of $A_{i}$ which is shown by $A_{i}{ }^{*}$ is calculated by the following equation:

$$
\begin{aligned}
& A_{i}^{*}=\frac{A_{i}^{-}}{A_{i}^{-}+A_{i}^{+}} \\
& i=1,2, \ldots, m .
\end{aligned}
$$




\section{FINDING}

Based on the used criteria and items to assess the social and economic sustainability of rural settlements, the raw data matrix of each criteria in the studied rural areas were collected through questionnaire and then the acquired scores of questionnaire for criteria was replaced through defined fuzzy numbers in membership function and finally, the total fuzzy scores was calculated for each indicator in each village. This was also repeated to other criteria in other villages. In the next step, in order to perform the model it is required to normalize indicators through conversion of fuzzy numbers to the real numbers in the fuzzy matrix of the data, which after the act of calculating, the obtained real numbers were formed the matrix of crisp numbers. At this stage, to express the relative importance of attributes and criteria should be determined their relative weight.

Accordingly, to calculate the relative weight is used Fuzzy Logic. Finally, the obtained weight bases on the opinions of 28 Council members will be multiplied by indicators to calculate the assessment of economic and social sustainability of rural settlements (Table 3 ). The weighted matrix of the main criteria in this study is as follows ${ }^{21}$.

The calculation of the weight of relative fuzzy to research indicators shows that in the first stage of TOPSIS - Fuzzy analysis, measurement of the index points in the CI, among all the studied dimensions the social dimension with 3.976 score, and ID C1 acquired the highest weight from the Council's point of view.

\footnotetext{
${ }^{1}$ : It should be noted that in Table (1), the fuzzy of the indicators of the allocated development funds is with ID (E1), Retrofitting rural houses with ID (E2), Substandard housing with ID (E3), rural road networks with ID (E4), rural power network and its backup service with ID (E5), population growth rate with ID (E6), training and educational facilities with ID (E7), clean drinking water with ID (E8), health facilities with ID (E9), The ICT offices with ID (E10), private residential homes with ID (E11), rural Islamic Council and Rural Municipality (Dehyari) with ID (E12), taking care of villages with cultural and historical monuments with ID (E13),
} 
Table (3): Ranking the socio - economic indicators of rural settlements emphasizing on the sustainable development approach

\begin{tabular}{|c|c|c|c|c|c|c|c|c|c|c|c|c|c|c|c|c|c|c|c|c|c|}
\hline & & \multicolumn{4}{|c|}{ D1 } & \multicolumn{4}{|c|}{ D2 } & \multicolumn{4}{|c|}{ D3 } & \multicolumn{4}{|c|}{ D4 } & \multicolumn{4}{|c|}{ D5 } \\
\hline \multirow{5}{*}{ C1 } & E1 & 0 & 0.08 & 0.08 & 0.27 & 0 & 0 & 0.08 & 0.27 & 0 & 0.32 & 0.3 & 0.8 & 0 & 0.08 & 0.08 & 0.27 & 0 & 0.2 & 0.2 & 0.54 \\
\hline & E2 & 0 & 0.2 & 0.2 & 0.54 & 0 & 0 & 0.08 & 0.18 & 0 & 0.32 & 0.3 & 0.8 & 0 & 0.2 & 0.2 & 0.54 & 0 & 0.2 & 0.2 & 0.54 \\
\hline & E3 & 0 & 0.08 & 0.08 & 0.27 & 0 & 0 & 0.04 & 0.27 & 0 & 0.2 & 0.2 & 0.5 & 0 & 0 & 0.04 & 0.18 & 0 & 0.08 & 0.08 & 0.27 \\
\hline & E4 & 0 & 0.2 & 0.2 & 0.54 & 0 & 0 & 0.08 & 0.81 & 0 & 0.08 & 0.1 & 0.3 & 0 & 0 & 0.04 & 0.18 & 0 & 0.08 & 0.08 & 0.27 \\
\hline & E5 & 0 & 0.32 & 0.32 & 0.81 & 0 & 0 & 0.32 & 0.18 & 0 & 0.32 & 0.3 & 0.8 & 0 & 0.08 & 0.08 & 0.27 & 0 & 0.32 & 0.32 & 0.81 \\
\hline \multirow{8}{*}{$\mathrm{C} 2$} & E6 & 0 & 0.2 & 0.2 & 0.54 & 0 & 0 & 0.04 & 0.27 & 0 & 0.2 & 0.2 & 0.5 & 0 & 0.2 & 0.2 & 0.54 & 0 & 0.32 & 0.32 & 0.81 \\
\hline & E7 & 0 & 0.08 & 0.08 & 0.27 & 0 & 0 & 0.08 & 0.54 & 0 & 0.32 & 0.3 & 0.8 & 0 & 0.2 & 0.2 & 0.54 & 0 & 0.2 & 0.2 & 0.54 \\
\hline & E8 & 0 & 0.08 & 0.08 & 0.27 & 0 & 0 & 0.2 & 0.54 & 0 & 0.32 & 0.3 & 0.8 & 0 & 0.08 & 0.08 & 0.27 & 0 & 0.08 & 0.08 & 0.27 \\
\hline & E9 & 0 & 0.08 & 0.08 & 0.27 & 0 & 0 & 0.2 & 0.27 & 0 & 0.32 & 0.3 & 0.8 & 0 & 0 & 0.04 & 0.18 & 0 & 0.08 & 0.08 & 0.27 \\
\hline & E10 & 0 & 0.2 & 0.2 & 0.54 & 0 & 0 & 0.08 & 0.81 & 0 & 0.32 & 0.3 & 0.8 & 0 & 0 & 0.04 & 0.18 & 0 & 0.32 & 0.32 & 0.81 \\
\hline & E11 & 0 & 0.32 & 0.32 & 0.81 & 0 & 0 & 0.32 & 0.54 & 0 & 0.32 & 0.3 & 0.8 & 0 & 0.32 & 0.32 & 0.81 & 0 & 0.32 & 0.32 & 0.81 \\
\hline & E12 & 0 & 0.2 & 0.2 & 0.54 & 0 & 0 & 0.2 & 0.27 & 0 & 0.2 & 0.2 & 0.5 & 0 & 0.2 & 0.2 & 0.54 & 0 & 0.32 & 0.32 & 0.81 \\
\hline & E13 & 0 & 0.08 & 0.08 & 0.27 & 0 & 0 & 0.08 & 0.27 & 0 & 0.08 & 0.1 & 0.3 & 0 & 0 & 0.04 & 0.18 & 0 & 0.08 & 0.08 & 0.27 \\
\hline
\end{tabular}

The economic dimension with 1.205 scores and ID (C2) is ranked second, which indicates that in order to achieve the goals of sustainable development in the studied villages, the importance of its economic aspect should also be regarded. Table (4) shows the rating of indices in each dimension according to the rural Council members.

Table (4): Ranking the socio - economic indicators of rural settlements emphasizing on the sustainable development approach in the villages surrounding of Sanandaj city

\begin{tabular}{|c|c|c|c|c|c|}
\hline & indicators & D & D & CI & Ranking \\
\hline \multirow{5}{*}{$\mathrm{C} 1$} & E1 & 14.0683 & 2.7650 & 16.8333 & 3 \\
\hline & E2 & 13.2580 & 5.7198 & 18.9778 & 2 \\
\hline & E3 & 14.1334 & 2.7148 & 16.8483 & 4 \\
\hline & E4 & 14.1304 & 2.6764 & 16.8068 & 5 \\
\hline & E5 & 13.0836 & 6.1399 & 19.2235 & 1 \\
\hline \multirow{8}{*}{$\mathrm{C} 2$} & E6 & 16.8215 & 16.6258 & 33.4473 & 3 \\
\hline & E7 & 15.7703 & 15.5314 & 31.3017 & 4 \\
\hline & E8 & 14.7579 & 14.4877 & 29.2456 & 5 \\
\hline & E9 & 20.7997 & 20.6215 & 41.4212 & 2 \\
\hline & E10 & 24.1073 & 23.7636 & 47.8709 & 4 \\
\hline & E11 & 26.7197 & 26.3877 & 53.1074 & 3 \\
\hline & E12 & 32.5432 & 32.2459 & 64.7891 & 2 \\
\hline & E13 & 39.5410 & 39.3768 & 78.9177 & 1 \\
\hline
\end{tabular}

The results of the final TOPSIS - FUZZY analysis for three dimensions of physical development in the studied indicators on rural areas surrounded by Sanandaj City show that economic dimension of the indicator (rural road networks) with ID (E5) and social dimension of the indicator (health facilities) with ID (E9) gained the lowest weights among the minimum, average and maximum fuzzy $\left(\widetilde{\boldsymbol{W}}_{i}\right)$. This suggest that to achieve the sustainable development in the studied rural areas, the indicators which gain the lower 
points are of more importance from experts' points of view and need to be considered to achieve the goals of the sustainable development in the study areas.

\section{CONCLUSIONS}

Development is essentially considered as a fundamental change in economic, social and cultural variables in each community and to realize development, coordination between its different aspects is necessary. Sustainable economic development is impossible without cultural, social and political development and cultural, social and political development is also impossible without rational and scientific approach toward long term economic development. On the other side, to coordinate sectoral and national goals with regional realities it is necessary to be considered sectoral policies in the context of wider and macro development policies. In the planning process, to achieve development and going along with this course, it is necessary to understand the various circumstances and requirements of human societies. It should be noted that rural development is not a concept apart from macro socio - economic development; it is considered as a part of the macro national development which emphasized more on the solving the problems associated with rural communities and trying to alleviate poverty and deprivation in these areas. Rural development as a concept and a set of experiences and different ways to organize production, improve welfare, and exchange in rural activities has a long history and is not unique to a particular country or system.

In this regard, the present study has attempted to assess and analyze physical and fabric development indicators of rural settlements in villages surrounding the city of Sanandaj using multi - criteria decision analysis methods. The rural areas surrounding the city of Sanandaj or inseparable urban sphere of influence include settlements which are highly economic, social, administrative, political and service dependent on Sanandaj City.These villages are mostly located in Humeh rural district. During recent years two villages of Naiser and Hassan Abad have been arrived the urban limits of Sanandaj and transferred their economic, social and environmental instability to Sanandaj City. The villages which are located in the inseparable urban sphere of influence are connected to Sanandaj through daily trips due to the proximity to the city and also due to lack of services in the villages and availability of services in the Sanandaj city. Mostly the villages have lost their rural function and in some of the villages (Asavale, Qar, Garmidar, Dolat Abad, Garizaeh, Nanleh, and Naiser) more than 60 percent of the rural workers are employed in Sanandaj. In most of these villages, more than 60 percent of employees are engaged in non-agricultural activities. All these factors indicate that villages located in the inseparable urban sphere of influence have lost their rural nature. 
According to the obtained results of the current situation study, in the current situation, social dimension with ID (C2) have been achieved more scores than other dimensions. Assessment of economic indicators indicate that almost all the villages have access to electricity and water facilities, so these indicators obtained higher values in the analysis. The indicators of housing and rural road networks obtained the lower value. It should be noted that the economy basis of these villages located surrounding the Sanandaj City is agriculture, with loss of soil quality, the active population seeking work entering the Sanandaj City and these villages will be played their role as dorms and over the time distance from their main function and turn into environments which are not applied for regional growth, but they are sending their additional burden of population towards cities. This should be considered in order to achieve sustainable rural development.

\section{REFERENCES}

[1]. Ahmadi et al, (2011), Tourists optimal path-finding by GIS(Case study: historical texture of Sanandaj), $5^{\text {th }}$ Symposium on Advances in Science \& Technology, 5thSASTech 12-17 May, 2011. Mashhad-Iran

[2]. Ataee, M. (2011), Multi - criteria fuzzy decision making, Publication of Shahrood Industrial University

[3]. Burger, Dietrich (1997), The political and social dimension of sustainable development. Presentation to the Workshop Sustainable development - Yeguare program,. Available on: http://www.cefe.net.

[4]. Cornelissen. A.M.G, Berg van den, Koops.W.J,Grossman. M,Udoa .H.M.J, Assessment of the contribution of sustainability indicators to sustainable development: a novel approach using fuzzy set theory, Agriculture, Ecosystems and Environment 86 (2001) 173-185.

[5]. Finland's Ministry of the Environment. (2007), Existing Assessment Tools and Indicators:

[6]. Greenwood J. ,(1999), Interpretations of Sustainable Agriculture in a Canadian Context, in Bryant, R. and Marois, C. (eds), The Sustainability of Rural Systems, 68-76, University of Montreal Montreal.

[7]. Husseini, A. \& Veisi R. \& Mohammadi M. (2010), Geographical zoning of restrictions of physical development of Rasht City using GIS, The fourth Conference on Planning and Urban Management, Mashhad, Iran.

[8]. Hussein Zadeh Dalir, K. Hushyar, H. et. al, (2006), Influential views, factors and elements in physical development of Iran's cities, Journal of Geography and Regional Development, N. 6.

[9]. Korenecki Veno (2005), Rural residential landuse strategy 
[10]. Kalantari Kh. (2008), Planning and regional development (theories and techniques), Khoshbin Publication, Tehran, Iran. Mose, Tun Lin and Pathranakul, Pairote(2006), an integrated approach to natural disaster prevention and management, vol 15, No 3, Emerald group publishing

[11]. Pur Taheri, M \& Rukn al-Din Eftekhari A. \& Badri, A. (2011), Strategies and policies of physical development of rural settlements with an emphasis on international and domestic experiences, Publication of Islamic Revolution Housing Foundation (Bonyad-e Maskan), $1^{\text {st }}$ edition, Tehran, Iran.

[12]. Mose, Tun Lin and Pathranakul, Pairote (2006), an integrated approach to natural disaster prevention and management, vol 15, No 3, Emerald group publishing

[13]. Torjman, Sherri (2000), The social dimension of sustainable development Caledon: Institute of social policy. Available on:

[14]. Lock, David. (2003), Planning for Sustainable Communities in Urban villages and the making of communities. London: Spon Press.

[15]. Qasemi Barfi, R. (2006), Management and organization of human forces in unexpected events, Second International Conference on Disaster Management, Tehran, Iran.

[16]. Zadeh, L., (1965). Fuzzy sets. Information and Control, 8, 38-53. 


\section{Y 20 res \\ Xnternational Research Journal}

p-ISSN 2202-2821 e-ISSN 1839-6518 (Australian ISSN Agency)

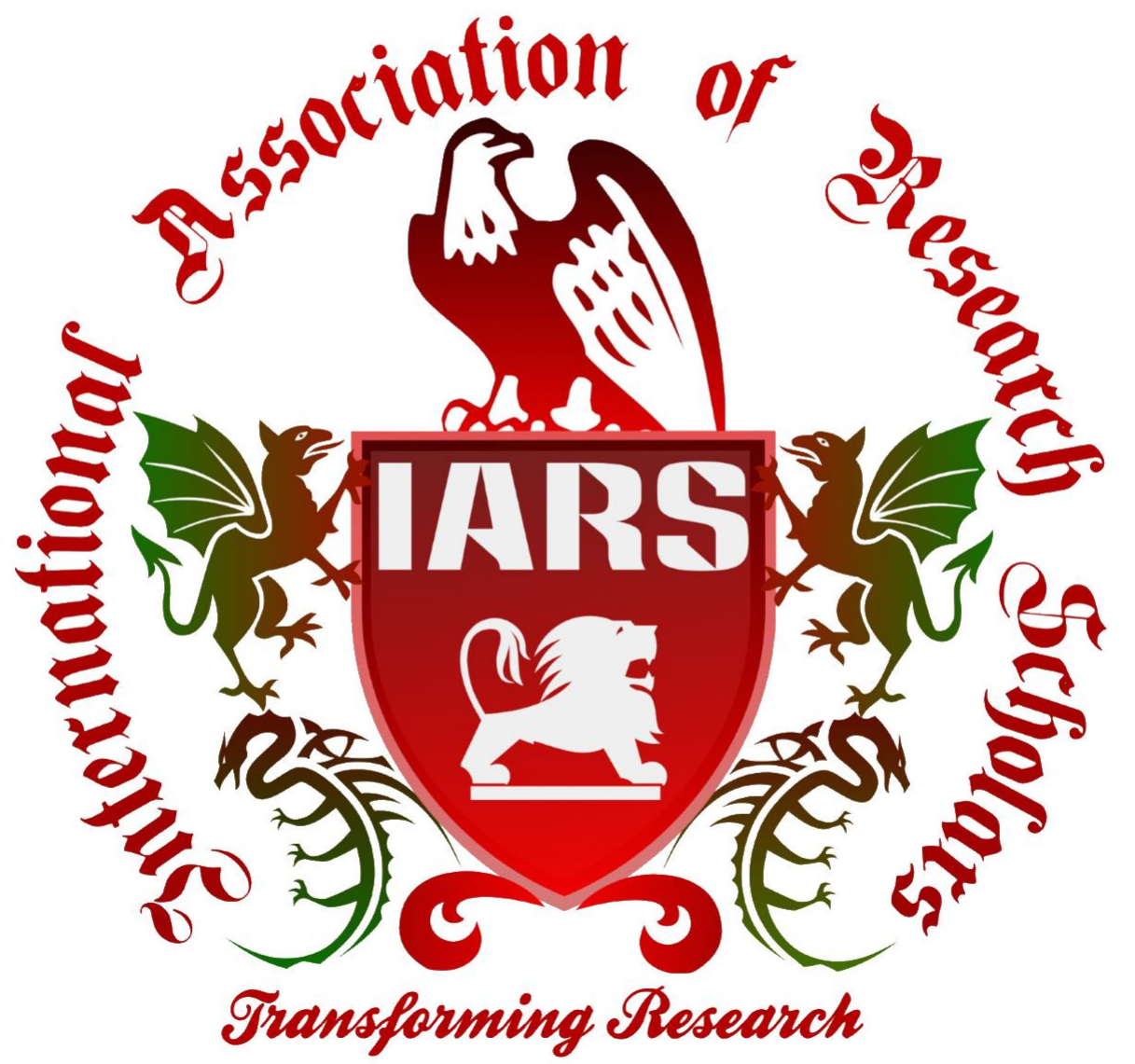

Since 2011 